\title{
Interrelationship of Potassium and Vagal Action on the Sinoatrial Pacemaker and on Atrioventricular Conduction *
}

\author{
Harvey Feigenbaum, $\dagger$ Charles M. Wunsch, $\$$ and Charles Fisch \\ (From the Department of Medicine [Division of Cardiology] and the Heart Research Center, \\ Indiana University School of Medicine, and the Krannert Heart Research Institute, \\ Marion County General Hospital, Indianapolis, Ind.)
}

In a previous communication, evidence was presented that elevation of plasma potassium from a mean control level of $3.4 \mathrm{mEq}$ per $\mathrm{L}$ to a mean of $6.1 \mathrm{mEq}$ per L inhibited or greatly reduced the ability of acetylcholine to induce atrioventricular (AV) block (1). These observations were made utilizing intermittent intracoronary injections of acetylcholine and intravenous infusion of potassium. The purpose of the present investigation was threefold: first, to study the interaction between potassium and endogenously liberated acetylcholine (vagal action) rather than exogenous acetylcholine as had been done previously; second, to determine if this interrelationship applies equally to $\mathrm{AV}$ transmission and impulse formation by the sinoatrial (SA) node; third, to eliminate by direct intracoronary injection of potassium the possibility that the results in the initial study were due to the peripheral effects of the cation.

\section{Methods}

Thirteen experiments were performed on twelve mongrel dogs weighing from 10.7 to $16.5 \mathrm{~kg}$. The animals were anesthetized with intramuscular morphine, $2.5 \mathrm{mg}$ per $\mathbf{~ k g}$, followed in 30 minutes by intravenous pentobarbital, $15 \mathrm{mg}$ per $\mathrm{kg}$. The dogs were intubated, and ventilation was controlled with a Harvard respirator. The ventilatory rate varied between 14 and 20 breaths per min-

\footnotetext{
* Submitted for publication June 26, 1964; accepted November 19, 1964.

Supported by the Herman C. Krannert Fund, the Indiana Heart Association, and the Indiana State Board of Health and in part by U. S. Public Health Service training grant 5363 and with facilities provided by Cardiovascular Clinical Research Center grant H-6308 from the National Heart Institute.

$\dagger$ Address requests for reprints to: Dr. Harvey Feigenbaum, Indiana University Medical Center, 1100 West Michigan St., Indianapolis 7, Ind.

$\ddagger$ Trainee, National Heart Institute.
}

ute with a tidal volume of 300 to $400 \mathrm{ml}$. The vagomimetic action of morphine $(2,3)$ accentuated the normal sinus arrhythmia. By controlling the rate and depth of ventilation, a reproducible form of sinus arrhythmia was maintained throughout the experiment. The electrocardiogram (ECG) and respiratory excursions were continuously monitored on an oscilloscope, and permanent recordings were made with an Electronics for Medicine recorder. The coronary arteries were catheterized via the external carotid artery by the method of West, Kobayashi, and Guzman (4). In this technique a 16-inch stainless steel catheter with a protective polyethylene sheath over its tip is inserted into the external carotid artery. The catheter is advanced to the root of the aorta, and then the tip is placed in either the right or left coronary artery.

In five of the experiments, the coronary needle was maneuvered into the right coronary artery, and with injection of approximately $0.1 \mathrm{mg}$ acetylcholine sinus arrest was produced, confirming the fact that the right coronary artery was entered and that the sinus node was being perfused. After the effect of acetylcholine was completely dissipated, an isotonic ( $155 \mathrm{mEq}$ per $\mathrm{L}$ ) solution of potassium chloride in distilled water was infused through the coronary needle at a mean rate of $2.25 \mathrm{ml}$ per minute for 15 to 30 seconds. The ECG was continuously recorded during the potassium infusion and was examined for any change in rate or rhythm of the sinus pacemaker.

In eight experiments the coronary needle was placed in the left coronary artery. Test doses of acetylcholine were again injected, and AV block was produced, confirming that the catheter was in the left coronary artery and that the AV transmission system was being perfused. An electrode catheter was then introduced into the right atrium via the right jugular vein and connected to a Grass stimulator. The atria were paced at a constant rate varying from 115 to 150 beats per minute from experiment to experiment. The rate was kept sufficiently rapid so that during each respiratory cycle second degree AV block occurred (Figure 1). After a minimum of five consecutive respiratory cycles, each of which produced at least 2:1 AV block, an isotonic potassium chloride solution was infused into the left coronary artery at the same rate as that for the right coronary injection. The ECG was continuously recorded and was examined 


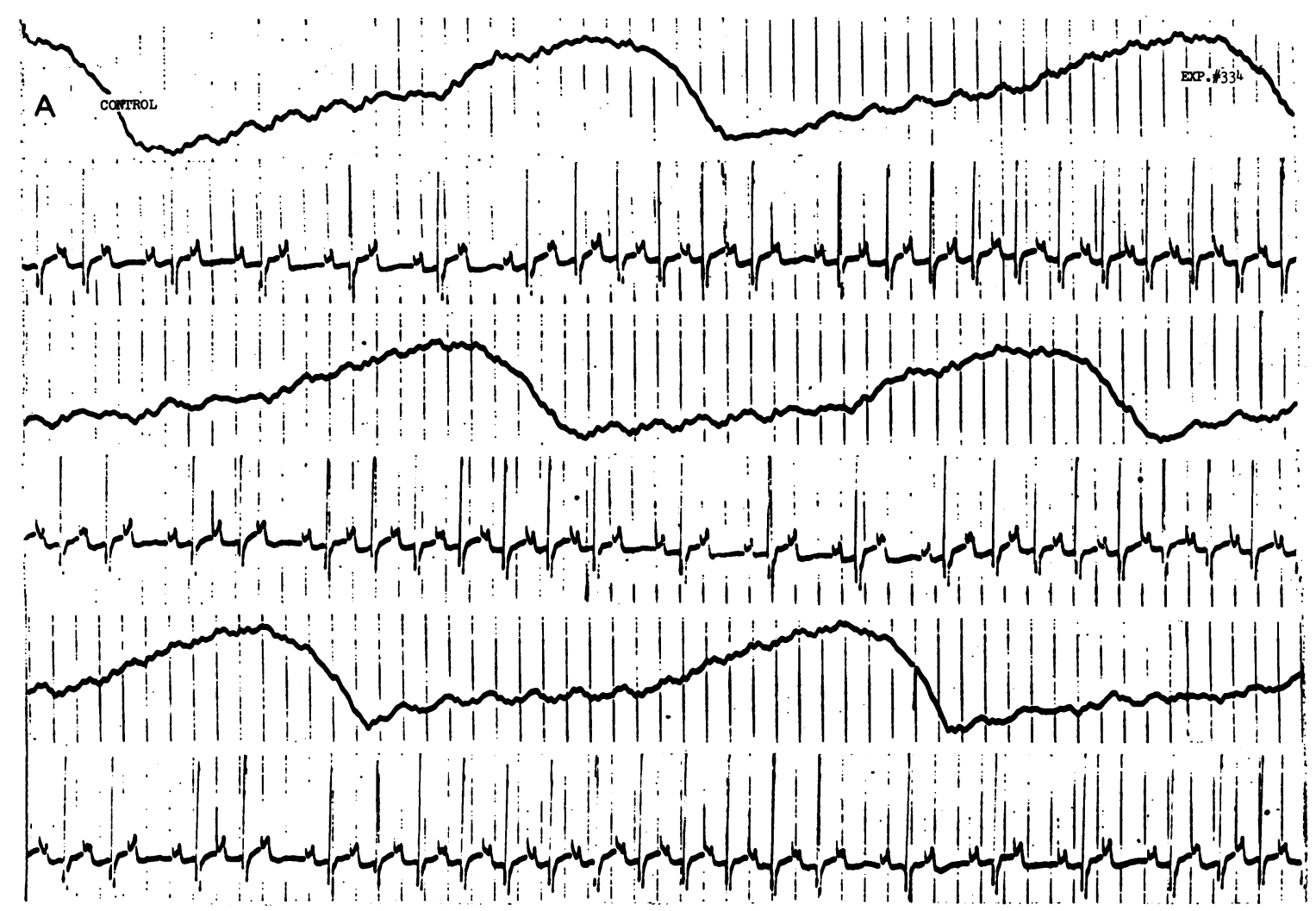

Fig. 1. Continuous tracing demonstrating Consistency with which atrioventricular (AV) BLock is RePRODUCED WITH EACH RESPIRATORY CYCLE. There is a pacemaker artifact preceding each $P$ wave. The wavy line above the ECG denotes variation in respiration. Upward deflections represent inspiration and downward deflections represent expiration. At least one nonconducted $P$ wave occurs during each respiratory cycle. ( $R$ waves are retouched.)

for changes in the configuration of the QRS, ST-T segment, and $\mathrm{T}$ wave and for changes in $\mathrm{AV}$ conduction.

As a control study, identical experiments were carried out with the substitution of sodium chloride for the potassium chloride.

\section{Results}

The ECG strips in Figure 2 demonstrate that 1) the insertion of the coronary catheter produced no demonstrable electrocardiographic changes, 2) the right coronary artery of the dog perfuses the SA node, as manifested by sinus arrest when acetylcholine was injected into the right coronary artery, and 3) the left coronary artery primarily perfuses the AV transmission system, as manifested by the appearance of AV block and only slight sinus bradycardia when acetylcholine was injected into the left coronary artery.

In the experiments in which the SA node was perfused with potassium, the mean control heart rate was $69 \pm 30$ with a variation from $59 \pm 25$ to $86 \pm 35$. This variation was due to sinus arrhythmia. With injection of the potassium into the right coronary artery, consistent changes of the ST segment or $\mathrm{T}$ wave or both were observed (Figure 3). This finding confirmed the fact that the cation was exerting a pharmacologic effect on the myocardium. However, there was no significant change in either the mean heart rate $(p=0.9)$ or the sinus arrhythmia $(p=0.6)$. The details of this group of experiments are presented in Table I.

In the second set of eight experiments, in which the heart was artificially paced, the second degree AV block was uniformly abolished within 5 to 10 seconds after the onset of the infusion of potassium into the left coronary artery (Figure 4). This action of potassium coincided with changes in the ST segment and $\mathrm{T}$ wave. Shortly after the infu- 


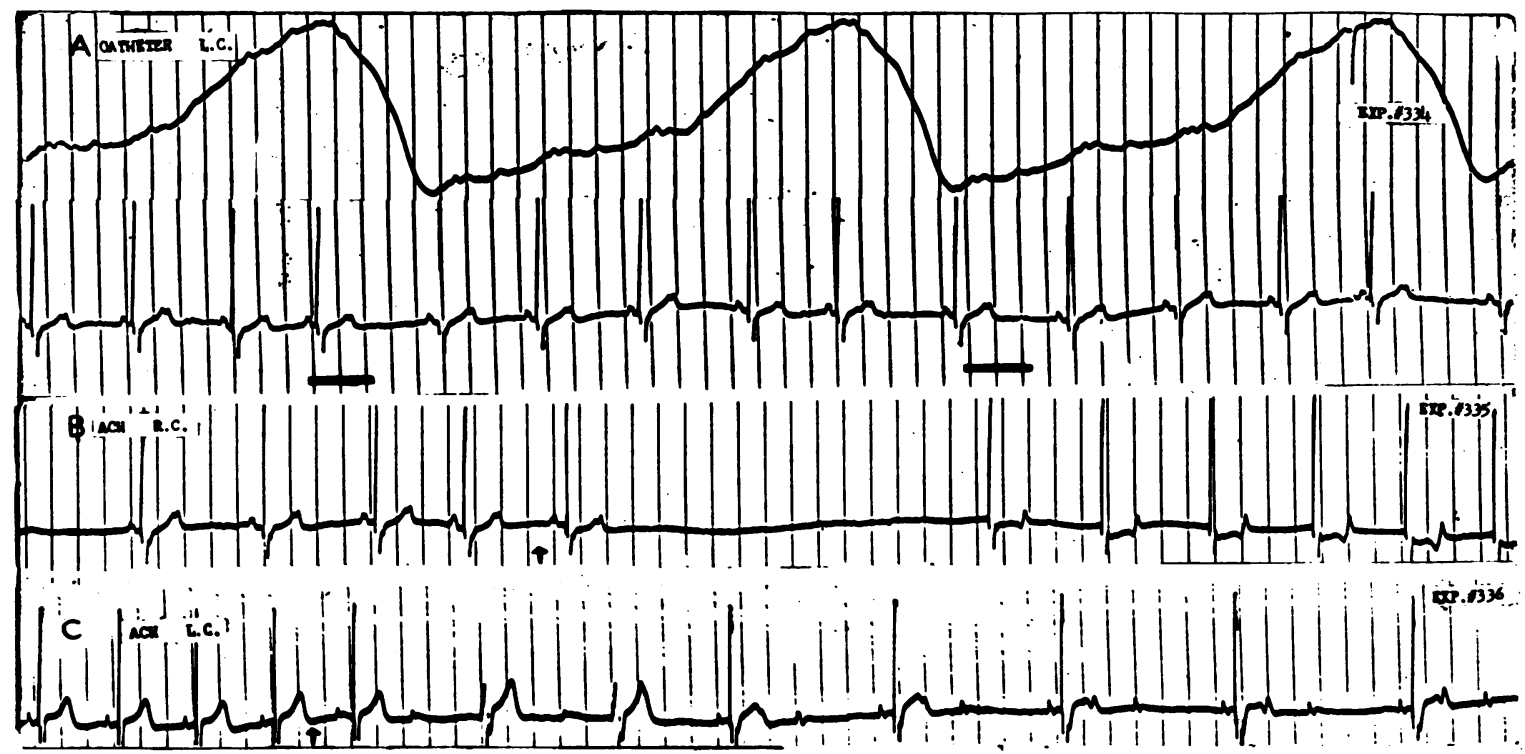

Fig. 2. Effect of intracoronary intubation. Tracing A demonstrates no change in the appearance of the ECG after the intracoronary needle is placed in the left coronary artery (second dark bar). Strip B illustrates the development of sinoatrial arrest after injection of acetylcholine into the right coronary artery, and the bottom tracing (strip C) demonstrates AV block when acetylcholine is infused into the left coronary artery. The arrows denote the time of injection of the acetylcholine in strips $B$ and $C$.

sion was stopped, the ST-T changes reverted to normal, and the phasic second degree AV block reappeared (Figure 4 ). The results of all the experiments in this group are presented in detail in Table II.

Control saline injections into the left coronary artery had no effect on either the ST-T segment or the AV block (Figure 5).

\section{Discussion}

This study utilized the facts that 1) morphine augments vagal action in the $\operatorname{dog}(2)$ and 2) sinus arrhythmia is vagally mediated (5) and may be used as an indicator of vagal activity. Thus by controlling the depth and rate of ventilation in a dog under the influence of morphine, it is possible to maintain a reproducible sinus ar-

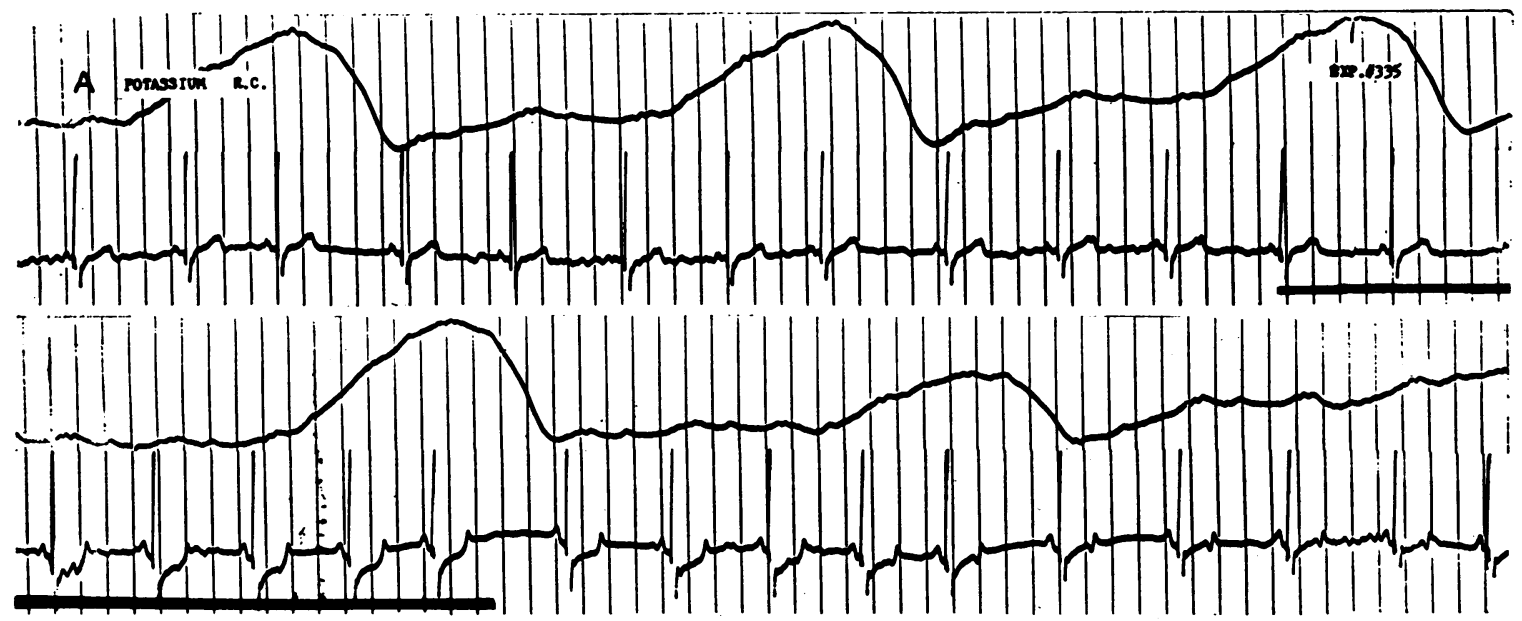

Fig. 3. Failure of potassium to alter sinoatrial pacemaker. The dark bar denotes infusion of potassium chloride into the right coronary artery. Although there are ST-T changes, there is no alteration in the rate or rhythm of the sinoatrial pacemaker. 
TABLE I

Effect of intracoronary potassium on sinoatrial pacemaker

\begin{tabular}{|c|c|c|c|c|c|c|c|c|c|}
\hline \multirow[b]{3}{*}{ Experiment } & \multirow[b]{3}{*}{ Infused $\mathrm{K}$} & \multicolumn{6}{|c|}{ Atrial rate } & & \\
\hline & & \multicolumn{3}{|c|}{ Before potassium } & \multicolumn{3}{|c|}{ After potassium } & \multicolumn{2}{|c|}{ Net change } \\
\hline & & $\begin{array}{l}\text { Variation } \\
\text { of rate dur- } \\
\text { ing sinus } \\
\text { arrhythmia }\end{array}$ & $\begin{array}{c}\text { Range } \\
\text { of rate } \\
\text { during } \\
\text { sinus ar- } \\
\text { rhythmia }\end{array}$ & $\begin{array}{l}\text { Mean } \\
\text { heart } \\
\text { rate }\end{array}$ & $\begin{array}{l}\text { Variation } \\
\text { of rate dur- } \\
\text { ing sinus } \\
\text { arrhythmia }\end{array}$ & $\begin{array}{l}\text { Range } \\
\text { of rate } \\
\text { during } \\
\text { sinus ar- } \\
\text { rhythmia }\end{array}$ & $\begin{array}{l}\text { Mean } \\
\text { heart } \\
\text { rate }\end{array}$ & $\begin{array}{c}\text { Range } \\
\text { of rate } \\
\text { during } \\
\text { sinus ar- } \\
\text { rhythmia }\end{array}$ & $\begin{array}{l}\text { Mean } \\
\text { heart } \\
\text { rate }\end{array}$ \\
\hline & $\begin{array}{l}m E q / k g \\
b o d y \text { wt }\end{array}$ & & & & & & & & \\
\hline 335 & 0.008 & $66-85$ & 19 & 72 & $63-88$ & 25 & 72 & +6 & 0 \\
\hline 338 & 0.009 & $52-96$ & 44 & 72 & $40-100$ & 60 & 70 & +16 & -2 \\
\hline 341 & 0.012 & $23-40$ & 17 & 26 & $27-43$ & 16 & 32 & -1 & +6 \\
\hline 342 & 0.005 & $94-136$ & 42 & 110 & $94-136$ & 42 & 118 & 0 & +8 \\
\hline 370 & 0.008 & $60-75$ & 15 & 66 & $60-83$ & 23 & 72 & +8 & +6 \\
\hline Average & 0.008 & $59-86$ & 27 & 69 & $57-90$ & 33 & 73 & +6 & +4 \\
\hline $\mathrm{SD}$ & \pm 0.003 & $\pm 25- \pm 35$ & \pm 15 & \pm 30 & $\pm 25- \pm 33$ & \pm 18 & \pm 30 & \pm 6.8 & \pm 3.9 \\
\hline $\mathrm{p}$ & & & & & & & & 0.6 & 0.9 \\
\hline
\end{tabular}

rhythmia throughout each experiment. Although stimulation of the nerve or the intracoronary inthis form of vagal stimulation may not be truly fusion of acetylcholine.

physiological, it is more so than either electrical The use of the intracoronary needle allows for

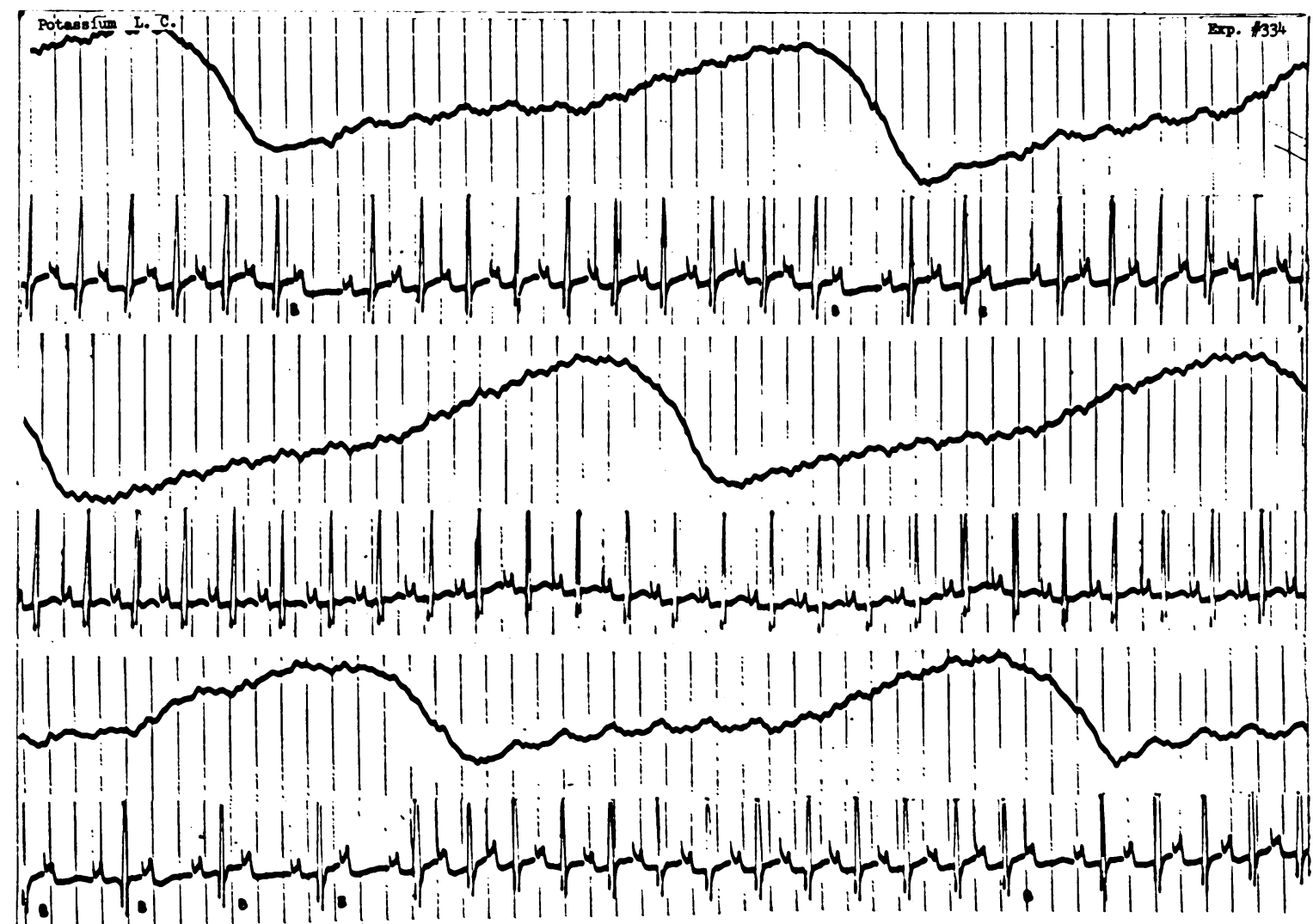

Fig. 4. Inhibition of AV block with potassium. Those $P$ waves that are not followed by ventricular depolarization are designated by the letter B. Before the potassium infusion (top tracing) there is at least one such $\mathrm{P}$ wave with each respiratory cycle. With infusion of potassium into the left coronary artery (middle tracing), the $T$ waves become elevated and every $\mathrm{P}$ wave is followed by a QRS complex. After the potassium is stopped (bottom tracing), the $\mathrm{T}$ waves return to control appearance and the second degree AV block reappears. 
selective perfusion of either the right or left coronary artery in a closed-chested animal, and thus advantage can be taken of the fact that in the dog the primary artery perfusing the SA node arises from the right coronary artery, whereas the area involved with $\mathrm{AV}$ transmission is supplied by the circumflex and anterior descending branches of the left coronary artery (6-10). In addition, by injecting relatively minute amounts of potassium $(0.0007 \mathrm{mEq}$ per $\mathrm{kg}$ at a rate of $0.33 \mathrm{mEq}$ per minute) directly into the coronary arteries, one obviates any possible peripheral effects of hyperkalemia, such as the release of catecholamines (3), changes in blood pressure, and the effects of pain due to the intravenous infusion of potassium (11). The minute amounts of potassium used in our experiments had an effect on the ECG comparable to that noticed when larger amounts of potassium were given faster by the intravenous route $(0.49 \mathrm{mEq}$ per $\mathrm{kg}$ given at a rate of 1.0 $\mathrm{mEq}$ per minute) (1).

When saline was substituted for potassium, there was no change in heart rate, sinus arrhythmia, AV conduction, QRS, or ST-T segment. This observation tends to rule out the coronary catheterization and the intracoronary injection of a nonoxygen-carrying solution as possible explanations for our findings.

The inhibition of the vagal-induced $\mathrm{AV}$ block by potassium and the failure of the cation to affect either sinus arrhythmia or the heart rate indicate a dissociation between the effects of potassium and vagal stimulation on the SA node and AV transmission system. With respect to AV transmission, the cation clearly acts in a direction
TABLE II

Effect of intracoronary $K$ on atrioventricular conduction

\begin{tabular}{|c|c|c|c|c|c|}
\hline \multirow[b]{2}{*}{$\begin{array}{l}\text { Experi- } \\
\text { ment }\end{array}$} & \multirow[b]{2}{*}{$\underset{\mathbf{K}}{\text { Infused }}$} & \multirow{2}{*}{$\begin{array}{c}\text { Atrial rate } \\
\text { with } \\
\text { pace- } \\
\text { maker }\end{array}$} & \multicolumn{3}{|c|}{$\begin{array}{l}\text { No. of blocked } P \text { waves } \\
\text { per respiratory cycle }\end{array}$} \\
\hline & & & $\underset{\mathbf{K}}{\text { Before }}$ & $\underset{\mathbf{K}}{\operatorname{During}}$ & $\underset{\mathbf{K}}{\text { After }}$ \\
\hline & $\begin{array}{l}m E q / k g \\
\text { body wt }\end{array}$ & & & & \\
\hline 331 & 0.006 & 150 & 2 & 0 & 2 \\
\hline 334 & 0.005 & 140 & 3 & $\mathbf{0}$ & 2 \\
\hline 335 & 0.007 & 125 & 2 & 0 & 2 \\
\hline 336 & 0.008 & 120 & 1 & 0 & 1 \\
\hline 337 & 0.005 & 115 & 2 & 0 & 2 \\
\hline 365 & 0.006 & 150 & 2 & 0 & 1 \\
\hline 366 & 0.005 & 136 & 3 & 0 & 3 \\
\hline 369 & 0.013 & 150 & 3 & 0 & 2 \\
\hline Mean & 0.007 & 136 & 2.3 & 0 & 1.9 \\
\hline SD & \pm 0.005 & \pm 40 & \pm 0.6 & \pm 0.0 & \pm 0.6 \\
\hline
\end{tabular}

opposite to that of the vagus. This finding is consistent with our earlier studies of the interrelationship of intravenously infused potassium and acetylcholine on AV transmission in an intact dog. This study showed that within a narrow plasma range of the cation (mean $6.1 \pm 0.8 \mathrm{mEq}$ per $\mathrm{L}$ ) the acetylcholine-induced AV block was inhibited (1). A similarly antagonistic effect of acetylcholine and potassium on AV transmission was demonstrated in the isolated perfused rabbit heart by Paes De Carvalho and Langan (12). This acceleration effect of potassium on conduction is in contrast with the AV block that is uniformly induced by potassium at much higher plasma levels of the cation (mean $8.3 \pm 0.76 \mathrm{mEq}$ per L) (13).

The failure of potassium to affect the action of the vagus on the SA node is in keeping with earlier studies of DeMello and Hoffman (14) on the isolated heart preparation. They showed that

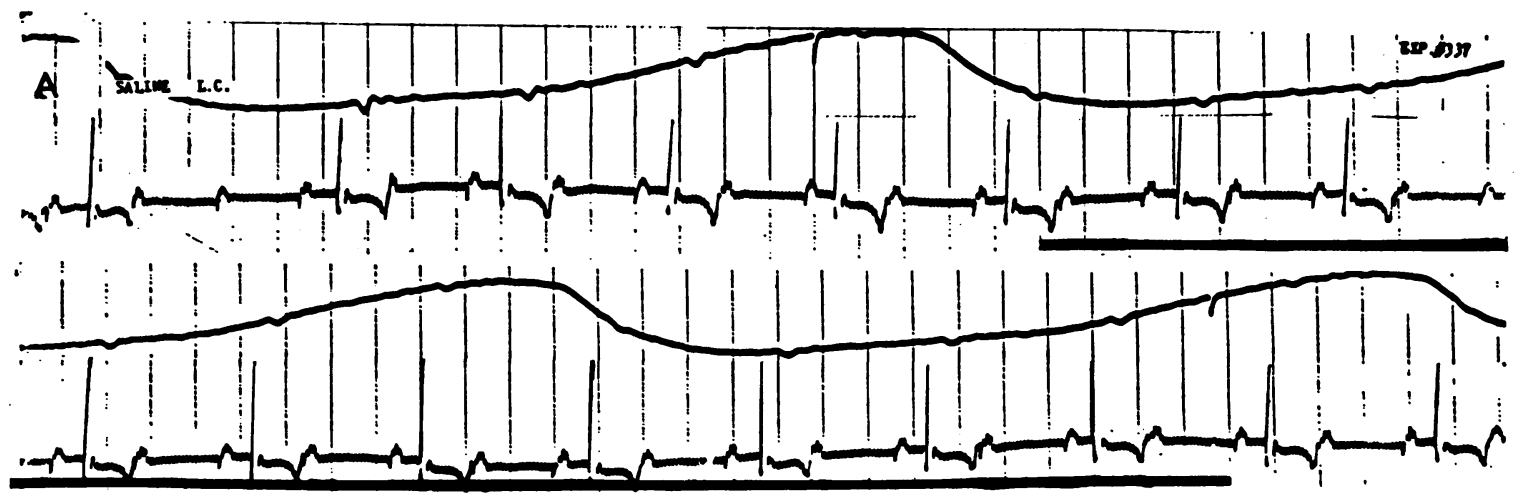

Fig. 5. EFFect of INTracoronary saline. With the infusion of saline (dark bar), there is no change in ST segment, $\mathrm{T}$ wave, or AV conduction as illustrated by a persistence of the second degree AV block. 
the SA node of the rabbit heart was extremely resistant to changing levels of potassium and that elevation of the extracellular potassium had little effect on the resting membrane potential or the slope of diastolic depolarization. These same workers, however, also noted that if the extracellular level of potassium were elevated, higher concentrations of acetylcholine were needed to produce slowing or arrest of the SA node, thus suggesting a possible antagonism between the two agents (15). On the other hand, potentiation of vagal action on the SA node at high plasma potassium levels was oserved by Botazzi (16), Howell (17), and Hoff, Humm, and Winkler (18). The differences between the observations of the earlier investigators and our findings might be explained by the differences in plasma potassium levels, strength of vagal stimulation, and the use of direct intracoronary infusion of the cation. In any event, the results of our studies demonstrate that intracoronary potassium in doses used in these experiments inhibits vagal-induced AV block but is without any effect on vagally mediated sinus arrhythmia.

Although the exact interrelationship between potassium and the vagus is not clear, some definite interdependence might be expected with the evidence that the primary mechanism of action of acetylcholine may be to increase the cell membrane's permeability to potassium (15). Moreover, the difference in the relationship between the vagus and potassium with respect to the SA node and the tissues involved with AV transmission is not entirely unexpected since the two areas differ both anatomically and functionally. The former is composed of relatively uniform pacemaker tissue, whereas the latter is made up of a group of anatomically different tissues that are concerned primarily with electrical conduction (19).

Transmission of electrical impulses depends upon the ability of the action potential of a given fiber to act as a stimulus and the ability of the adjoining fiber or group of fibers to respond. The intensity of the stimulus is greater when the amplitude and the rate of rise of the action potential is greater. On the other hand, the ability of the fiber to respond is influenced to some extent by its resting and threshold potentials. Experimental evidence suggests that acetylcholine may impair
$\mathrm{AV}$ conduction by altering the action potential of the transitional fibers located at the atrionodal junction (15). The slope of phase $\mathrm{O}$ and the amplitude of the action potential of these fibers are both decreased by either acetylcholine or vagal stimulation (19). Thus the resultant action potential is less effective as a stimulus. On the other hand, mild hyperkalemia may accelerate AV conduction by lowering the resting membrane potential of the adjoining fibers; consequently, a lesser stimulus is required to reduce the resting potential to the threshold level from which a response is elicited.

With the membrane becoming more permeable to potassium, the potassium gradient theoretically becomes more influential in determining the electrical potentials across the membrane. The findings of Trautwein and Dudel (20) and Burgen and Terroux (21) that acetylcholine acts to bring the resting transmembrane potential of an atrial fiber closer to a potassium equilibrium potential in the presence of a changing extracellular potassium tend to support this theory. Thus if acetylcholine inhibits AV conduction by altering the action potential of the fibers at the atrionodal junction and if this alteration in action potential is a function of increased membrane permeability to potassium, then a change in the potassium gradient might theoretically modify the effect of acetylcholine on the action potential and in turn AV conduction. Thus the antiacetylcholine effect of potassium with respect to AV transmission may result from direct interference with the vagal effect on the monophasic action potential.

Although impulse transmission is largely dependent on the magnitude and rate of rise of the action potential, the rate of impulse formation is largely a function of the slope of the resting potential during phase 4. Acetylcholine depresses the rate of discharge of the SA pacemaker by decreasing this slope (15). It is likely that potassium does not affect this phase of the action potential (14), thus explaining the failure of potassium to inhibit the action of the vagus on the SA pacemaker.

There is also evidence that all phases of the monophasic action potential of the SA node are relatively insensitive to changes in extracellular potassium (15). Thus the possibility remains that the observed differential response to potassium 
with respect to the SA node and AV transmission system is due to relative differences in potassium sensitivity of the different cardiac fibers rather than to a selective action of the cation on any particular component of the monophasic action potential.

\section{Summary}

Selective intracoronary injections of potassium chloride were made in mongrel dogs whose vagal tone was accentuated with morphine. Perfusion of the atrioventricular (AV) conduction system with potassium consistently inhibited vagal-induced AV block; however, similar perfusion of the sinoatrial (SA) node had no effect on vagal-induced sinus bradycardia or sinus arrhythmia.

The results confirm previous observations that moderate hyperkalemia and acetylcholine are antagonistic with respect to AV conduction. The failure of potassium to alter the vagal influence on the sinus pacemaker demonstrates that the interrelationship of potassium and the vagus is not uniform for all cardiac tissues and for all electrophysiologic events. Some possible explanations for this differential effect of the two agents are discussed.

\section{References}

1. Fisch, C., H. Feigenbaum, and J. A. Bowers. The inhibition of acetylcholine-induced atrioventricular block by potassium. J. clin. Invest. 1963, 42, 563.

2. Cohn, A. E. The effect of morphine on the mechanism of the dog's heart after removal of one vagus nerve. J. exp. Med. 1913, 18, 715.

3. Goodman, L. S., and A. Gilman. The Pharmacological Basis of Therapeutics. New York, Macmillan, 1955, pp. 230, 802.

4. West, J. W., T. Kobayashi, and S. V. Guzman. Coronary artery catheterization in the intact dog. Circulat. Res. 1958, 6, 383.
5. Best, C. H., and N. B. Taylor. Physiological Basis of Medical Practice. Baltimore, Williams \& Wilkins, 1950, p. 240.

6. Lumb, G., R. S. Shacklett, and W. A. Dawkins. The cardiac conduction tissue and its blood supply in the dog. Amer. J. Path. 1959, 35, 467.

7. Halpern, M. H. Arterial supply to the nodal tissue in the dog heart. Circulation 1954, 9, 547.

8. Pianetto, M. B. The coronary arteries of the dog. Amer. Heart J. 1939, 18, 403.

9. James, T. N. Anatomy of the Coronary Arteries. New York, Hoeber, 1961, p. 162.

10. James, T. N., and R. A. Nadeau. Direct perfusion of the sinus node: an experimental model for pharmacologic and electrophysiologic studies of the heart. Henry Ford Hosp. Bull. 1962, 10, 21.

11. Fenn, W. O. The role of potassium in physiological processes. Physiol. Rev. 1940, 20, 377.

12. Paes De Carvalho, A., and W. B. Langan. Influence of extracellular potassium levels on atrioventricular transmission. Amer. J. Physiol. 1963, 205, 375.

13. Fisch, C., H. Feigenbaum, and J. A. Bowers. The effect of potassium on atrioventricular conduction of normal dogs. Amer. J. Cardiol. 1963, 11, 487.

14. DeMello, W. C., and B. F. Hoffman. Potassium ions and electrical activity of specialized cardiac fibers. Amer. J. Physiol. 1960, 199, 1125.

15. Hoffman, B. F., and P. F. Cranefield. Electrophysiology of the Heart. New York, McGrawHill, 1960, pp. 110, 116, 145.

16. Bottazi, quoted by W. H. Howell. Arch. Physiol. 1896, 882.

17. Howell, W. H. Vagus inhibition of the heart and its relation to the inorganic salts of the blood. Amer. J. Physiol. 1906, 15, 280.

18. Hoff, H. E., D. G. Humm, and A. W. Winkler. Concentration of potassium in serum and response to vagal stimulation in the dog. Amer. J. Physiol. 1944, 142, 627.

19. Paes De Carvalho, A., W. C. DeMello, and B. F. Hoffman. The Specialized Tissues of the Heart. Amsterdam, Elsevier, 1961, pp. 22, 147.

20. Trautwein, W., and J. Dudel. Zum Mechanisnus der Membranwirkung des Acetylcholin an der herzmuskelfoser. Pflügers Arch. ges. Physiol. 1958, 266, 324.

21. Burgen, A. S. V., and K. G. Terroux. On the negative inotropic effect in the cat's auricle. J. Physiol. (Lond.) 1953, 119, 139. 